\title{
Statistic and genetic parameters of 205-day weaning weight of beef calves
}

\author{
Ferenc Szabó', Eszter Szabó ${ }^{2}$ and Szabolcs Bene ${ }^{3}$ \\ 'University of West Hungary, Hungary, ${ }^{2}$ University of Kaposvár, Hungary, ${ }^{3}$ University of Pannonia, Hungary
}

\begin{abstract}
The aim of the study was to do genetic evaluation of the 205-day weaning weight of pure bred herds of different beef cattle breeds kept in Hungary and supply results for genetic programmes of different breeds.

Population genetic analysis was performed on data from 42695 purebred beef calves from seven breeds born from 1981 to 2005 in Hungary. Animal model was used for the estimations. Sire, herd, age of dam at calving, birth year, season of birth and sex of calf had significant effects on 205-day calf weaning weight for each breed. Significant breed differences and breed overlaps were found. Direct heritability value estimates were 0.18 to 0.61 , the maternal heritability values from 0.07 to 0.38 , and the total heritability values were between 0.09 and 0.35 . The direct-maternal genetic correlations were high and negative for all the breeds varying from -0.63 to -0.88 .
\end{abstract}

Keywords: beef cattle, breeds, weaning weight, breed differences and overlap, heritability, genetic correlations

\section{Introduction}

Weaning weight in beef cattle is a trait of major economic importance because the weaned calf is the end product and almost total output of the cow-calf unit. On the other hand it is a complex trait since it reflects not only the growth ability of calf but also the maternal environment created for the calf by its dam. Moreover weaning weight is influenced by some other effects such as sex of the calf, age of dam, birth year, birth season etc. Weaning weight adjusted to 205 day of age is very important selection criteria in the breeding programs even so, measuring and evaluating of this trait is essential part of performance test and breeding value estimation.

In Hungary only a few beef calves are fattened and slaughtered, most of them are sold abroad, so the country is mostly interested in weaning weight. From this situation one of the aims of different breed associations is to improve the weaning weight of their breed whether it is Hereford or Charolais. For breed decision the weaning weight or 205-day weaning weight of the calves of different cows kept in various environments is very important information.

General practice for appropriate weaning weight evaluation and comparison is adjusting weaning weight to 205 days of age. For the applying breeding programmes we have to know the weaning results, variation, co-variation components and genetic parameters of them. Among genetic parameters heritability is important, measure of the proportion of genetic 
variation within the total phenotypic variation. Also, correlation between different effects is important for breeding programmes.

There are numerous studies that have examined weaning weight of different beef cattle breeds and the influence of environmental and genetic effects (Minyard \& Dinkel 1965, Sellers et al. 1970, Smith et al. 1976, Notter et al. 1978, Pell \& Thayne 1978, Gregory et al. 1979, Amer et al. 1992, Meyer et al. 1994, Cundiff et al. 1998, Szabó et al. 2006, Vergara et al. 2009). Also there are data for breed differences breed overlap and genetic trend from North America (Sullivan et al. 1999).

While a number of these authors have reported heritability values for weaning weight including data for the maternal effect, according to Meyer et al. (1994) and Vergara et al. (2009) further research is required to separate the direct and maternal genetic components for better estimation of genetic values in beef cattle populations.

The aim of the study was to do genetic evaluation of the 205-day weaning weight of pure bred herds of different beef cattle breeds kept in Hungary and supply results for genetic programmes of different breeds.

The primary objective of this study, using data from pure bred cattle populations in Hungary, was to evaluate environmental and genetic effects on weaning weight. Also, direct and maternal heritabilities, together with direct-maternal genetic correlations, were estimated.

\section{Material and methods}

Population genetic analysis was performed on data from 42695 purebred beef calves from seven breeds, Hungarian Grey, Limousin, Hereford, Angus, Charolais, Hungarian Simmental and Blonde d'Aquitaine, born between 1981 and 2005 in Hungary. Performance and complete pedigree data were recorded by the breed associations. Practically all records available in the given period for Hungarian purebred beef calves were used for the evaluation. The number of calf records can be seen in Table 1. As it can be seen from the table three generations (progeny, parents, and grand parents) were considered in the study.

The beef herds from which the data originated were all on different farms. Cows were mated using both artificial insemination and natural service to produce straightbred calves. The majority, $70-75 \%$ of calvings took place in spring, $10-15 \%$ of calvings were in winter, $5-10 \%$ was in summer, and 4-8\% was in autumn. The calves remained with their dams on pasture. As creep feeding is not a common practice in beef production in Hungary, data for this effect were not available in the dataset of breed organizations. So, the effect of creep feeding was not taken into consideration during this study. The calves were weighed on the day of birth and at weaning. Weaning weights and corresponding ages were recorded between 150 and 240 days age. Calf weaning weight was adjusted to 205 days of age by linear interpolation from birth weight, weaning weight and age. The calculation of 205 day weaning weight was as follows:

$$
A=\frac{B-C}{D} \times 205+C
$$

where $A$ is 205 days weight $(\mathrm{kg}), B$ is the weaning weight $(\mathrm{kg}), C$ is the birth-weight $(\mathrm{kg}), D$ is the weaning age (days). 
Due to the calculation the calf age effect could be eliminated as all calves were considered to be at the same age. During the adjustment only the afterbirth gain was counted that is why difference of weaning weight (B) and birth-weight $(C)$ was taken. This difference was divided by weaning age $(D)$ in order to get daily gain between birth and weaning date. Total gain was adjusted to 205 days of age with multiplying daily gain by 205 . Finally birth weight (C) was added to the product, because it is part of the total weaning weight.

Table 1

Summary of data used for genetic evaluation

\begin{tabular}{lrrrrrrr}
\hline & HG & HS & AA & HE & CH & BD & LI \\
\hline $\begin{array}{l}\text { Period of records } \\
\text { Number of herds }\end{array}$ & 9 & 2 & 2 & 2 & 12 & 2 & $1992-2005$ \\
$\begin{array}{l}\text { of calves } \\
\text { of sires }\end{array}$ & 5720 & 7032 & 2451 & 5109 & 13087 & 3250 & 6046 \\
$\begin{array}{l}\text { of dams } \\
\text { of paternal }\end{array}$ & 2632 & 232 & 63 & 119 & 146 & 27 & 55 \\
$\begin{array}{l}\text { grand sires } \\
\text { of maternal }\end{array}$ & 35 & 17 & 13 & 18 & 44 & 3 & 8 \\
$\begin{array}{l}\text { grand sires } \\
\text { of paternal }\end{array}$ & 105 & 114 & 19 & 55 & 101 & 20 & 34 \\
$\begin{array}{l}\text { grand dams } \\
\text { of maternal }\end{array}$ & 50 & 24 & 31 & 32 & 69 & 4 & 16 \\
grand dams & 702 & & 119 & 234 & 990 & 429 & 558 \\
\hline
\end{tabular}

HG: Hungarian Grey, HS: Hungarian Simmental, AA: Angus, HE: Hereford, CH:Charolais, BD: Blonde d'Aquitaine, LI: Limousin

However, Rossi et al. (1992) suggested the age of calf to be included in the evaluation model as a covariate, according to Hungarian Beef Recording Guideline (1996) weaning weight data were pre-adjusted by linear model to 205 days of age and the adjusted weaning weight data were used in the model applied in this study.

Although Rumph \& Van Vleck (2004) suggested quadratic model for some effects mostly for effect of age of dam on weaning weight, moreover separated evaluations for male and female calves. As our previous study did not show significance between linear and quadratic model, furthermore we did not find different maternal effect between male and female calves, linear model was used and male and female calves were evaluated together in this study. Sex of calf was just put as a fixed effect into the model.

There can be many effects on weaning weight, however only some more important ones can be and are registered by breed associations. So, sire, herd, age of cow at calving, birth year, birth season and sex of calves were considered and used in the model as a fixed effects. The number of groups (steps) within each effect was as follows: 27-232 sires, 2-12 herds, 12 (from 2 to 14 years) age groups of cows, 26 (from 1981 to 2005) birth yeas groups, 4 (spring, summer, autumn, winter) birth season groups and 2 (male and female) sex groups by breed.

The random part of evaluation, the maternal permanent environmental effect could be evaluated by the applied model, because all cows involved in the evaluation were recorded and had at least two calves. No significant difference was between breeds by the number of calves per cow. 
The effect of contemporary group was not considered, as the evaluation was done separately by breed, however there was a farm where cows of different breeds were kept together and their purebred calves were raised in the common management group.

The 205-day weaning weights were analysed using animal model. The software used to evaluate the significance of environmental and genetic effects was Harvey's (1990) Least Squares Maximum Likelihood, Derivative Free Restricted Maximum Likelihood (DFREML) Computer Program (Meyer 1998). To estimate genetic parameters and breeding values the Multitrate Derivative Free Restricted Maximum Likelihood (MTDFREML) program developed by Boldman et al. (1993) was used. This programme can consider the number of generations as well as the existence of genetic associations between different populations of a given breed evaluated.

However MTDFREML is and appropriate method to evaluate the population genetic parameters, but do not inform us about the significance of fixed effects. As we were interested in the significance of mentioned fixed effects, DFREML was used for pre-evaluation.

The animal model was as follows:

$$
\hat{y}=X b+Z u+W m+S p e+e
$$

where $\hat{y}$ is the vector of observation (trait), $X$ is the matrix of fixed effects, $Z$ is the matrix of random effects, $W$ is the matrix of maternal genetic effect, $S$ is the matrix of maternal permanent environmental effect, $\boldsymbol{e}$ is the residual, $\boldsymbol{b}$ is the vector of fixed effects, $\boldsymbol{u}$ is the vector of random effects, $\boldsymbol{m}$ is the vector of maternal genetic effects, $p e$ is the vector of maternal permanent environmental effects.

Breed differences and breed overlap was evaluated on the basis of breed means and distribution. Genetic trend in breeds was estimated based on the breeding value data supplied by MTDFREML. Overall mean breeding value, which was considered as a zero, was calculated for the whole period of estimation for all seven breeds. A yearly breeding value of a given breed was determined by the deviation of its breeding value from the overall mean value. The genetic trend representing the evaluated breeds was described by lines of yearly changes of breeding value.

\section{Results and discussion}

Sire, herd (except for Blonde d'Aquitaine), age of dam at calving, birth year, season and sex of calf all had significant effects $(P \leq 0.05)$ on 205-day weaning weight of calves in each breed. These findings correspond to the results of others reported in the literature (Minyard \& Dinkel 1965, Sellers et al. 1970, Pell \& Thayne 1978, Gregory et al. 1979, Cundiff et al. 1975, 1998, Szabó et al. 2006) who also found significant effects of one or more of the factors mentioned on weaning performance.

The statistic for weaning weight by breed can be seen in Table 2, while the distribution of 205-day calf weight of the evaluated breeds is shown in Figure 1.

The breed mean 205-day weaning weight varies between $191-242 \mathrm{~kg}$, while that of the standard deviation between $30-41 \mathrm{~kg}$. Coefficient of variation values are below $20 \%$ in all seven breeds. The rank of breeds according to the increasing mean values of 205-day weaning weigh is: Hungarian Grey, Limousin, Hereford, Angus, Charolais, Hungarian Simmental and 
Blonde d' Aquitaine. Breed data show normal distribution. The range within breeds is higher than the mean values in case of each breed. The difference between the mean values of the bottom Hungarian Grey and the top Blonde d' Aquitaine is $51 \mathrm{~kg}$, which are approximately quarter of the all breeds mean and one third one sixth of the range observed within breeds. The results are similar to findings of Cundiff et al. (1975) who reported that breed differences are generally smaller than the within breed variances.

Table 2

Statistics of 205-day weight data of calves

\begin{tabular}{|c|c|c|c|c|c|c|c|c|}
\hline Breed & & $\mathrm{HG}$ & $\mathrm{HS}$ & AA & $\mathrm{HE}$ & $\mathrm{CH}$ & $B D$ & $\mathrm{LI}$ \\
\hline $\begin{array}{l}\text { Number of calves } \\
\text { 205-day weight, kg }\end{array}$ & & 5720 & 7032 & 2451 & 5109 & 13087 & 3250 & 6046 \\
\hline Mean & & 191 & 236 & 212 & 204 & 227 & 242 & 203 \\
\hline SE & & 5.05 & 3.40 & 3.61 & 5.06 & 8.58 & 7.95 & 2.99 \\
\hline SD & & 30.15 & 39.48 & 36.19 & 38.90 & 40.87 & 37.03 & 35.15 \\
\hline$C V, \%$ & & 16.54 & 16.30 & 16.84 & 18.66 & 18.01 & 15.16 & 16.97 \\
\hline Range & & 223 & 250 & 266 & 266 & 299 & 263 & 257 \\
\hline \multicolumn{9}{|c|}{ Deviation from overall mean value, $\mathrm{kg}$} \\
\hline \multirow[t]{13}{*}{ Age of dam, year } & 2 & - & -16 & -15 & -20 & -15 & - & -18 \\
\hline & 3 & -5 & -7 & -5 & 0 & -12 & -6 & -13 \\
\hline & 4 & 0 & 8 & 3 & 7 & -1 & -5 & -5 \\
\hline & 5 & 2 & 11 & 5 & 15 & 4 & -4 & 2 \\
\hline & 6 & 1 & 15 & 6 & 15 & 7 & -2 & 8 \\
\hline & 7 & 5 & 15 & 10 & 12 & 7 & 0 & 8 \\
\hline & 8 & 4 & 15 & 6 & 11 & 4 & 0 & 12 \\
\hline & 9 & 5 & 12 & 1 & 8 & 6 & -1 & 10 \\
\hline & 10 & 1 & 10 & 0 & 6 & 8 & 8 & 8 \\
\hline & 11 & 3 & 6 & -3 & 6 & 2 & 7 & 8 \\
\hline & 12 & -3 & -3 & -7 & 0 & -1 & 6 & 4 \\
\hline & 13 & 2 & -1 & - & -7 & -4 & 1 & 3 \\
\hline & 14 & -6 & -5 & - & -11 & -11 & 1 & 0 \\
\hline \multirow[t]{4}{*}{ Birth season } & Winter & -3 & 3 & 5 & -14 & -2 & 9 & 5 \\
\hline & Spring & 7 & 2 & 7 & -2 & -2 & 7 & 7 \\
\hline & Summer & 14 & -6 & -6 & 17 & -2 & -16 & -11 \\
\hline & Autumn & -20 & 2 & -5 & - & 4 & - & -1 \\
\hline \multirow[t]{2}{*}{ Sex of calf } & Male & 9 & 8 & 8 & 6 & 7 & 5 & 7 \\
\hline & Female & -10 & -8 & -8 & -5 & -7 & -5 & -7 \\
\hline
\end{tabular}

HG: Hungarian Grey, HS: Hungarian Simmental, AA: Angus, HE: Hereford, CH: Charolais, BD: Blonde d'Aquitaine, LI: Limousin

Both the data in the table and the figure show breed overlap. Approximately $50 \%$ cent of 205-day weaning weight data fit to all breeds. $20-30 \%$ of the Hungarian Grey calves are heavier than the average of Hereford, Angus and Limousin and 10-20\% of them are heavier than the bottom $10-20 \%$ of the top Blonde d' Aquitaine breed's calves. These results are similar to observation of Sullivan et al. (1999) who found that substantial breed overlap exists in many regions of North America. For example $1 \%$ of Angus, $3 \%$ of Limousin and $6 \%$ of Hereford were above the Simmental mean as for the weight gain between birth and weaning in their study. 
The variance components and heritability value estimates obtained from the animal model are shown in Table 3.

The standard errors for the estimated heritabilities are rather high in some cases. These results can be explained by the situation that herds of the evaluated breeds were kept not in the same environmental conditions, but rather in different farms. Different farms gave different nutrition, management etc. conditions that resulted high phenotypic variation (phenotypic standard deviation values). The fairly high variance resulted in higher standard errors, than it would be expected in population with herds kept in similar environment. In the relevant literature when the situation is like the present study, there are similarly high standard errors of the heritability values. For example Dodenhoff et al. (1999) have reported values of standard error $0.4-0.5$ for the heritability values of weaning weight of different beef cattle breeds.

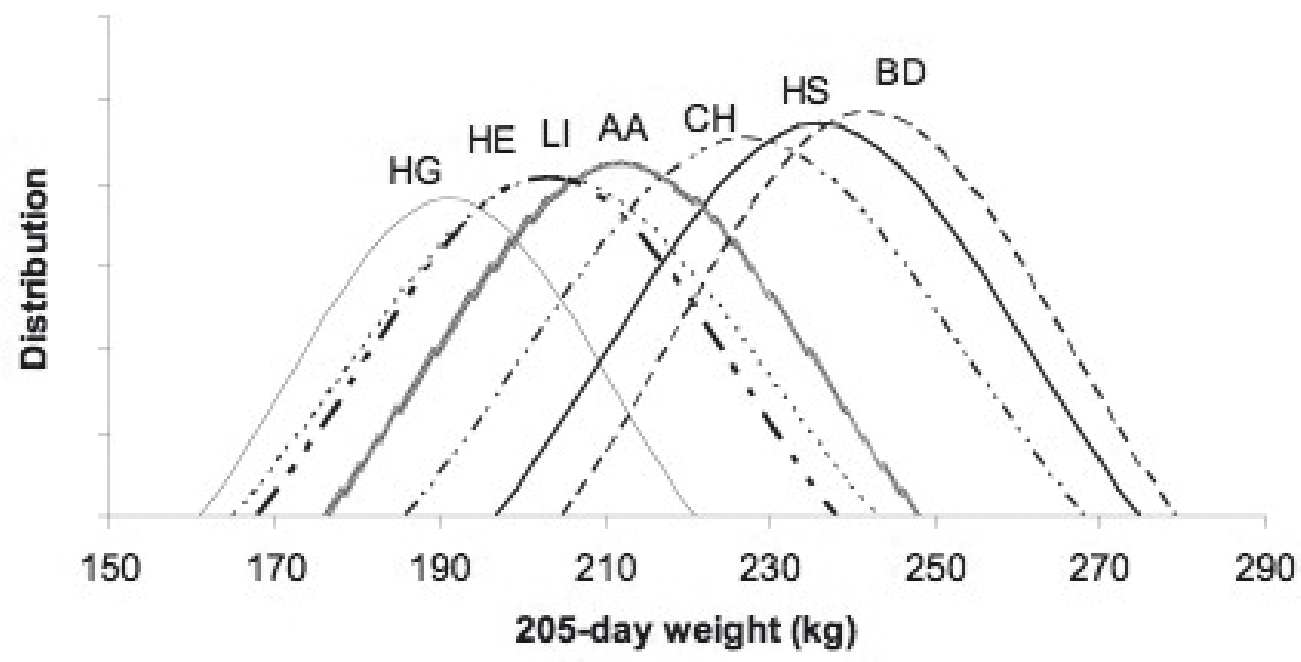

$\longrightarrow \mathrm{HG} \longrightarrow \mathrm{HS}-\mathrm{AA} \cdots \cdots \cdot \mathrm{HE}-\cdots \cdot \mathrm{CH}----\mathrm{BD}-\cdots \mathrm{LI}$

Figure 1

The distribution of 205-day weaning weight of different breeds

HG: Hungarian Grey, HS: Hungarian Simmental, AA: Angus, HE: Hereford, CH: Charolais, BD: Blonde d'Aquitaine, Ll: Limousin, The vertical top points in the figure are the mean values $(\mathrm{kg})$ by breeds, while the horizontal ranges are mean values $\pm \mathrm{s}(\mathrm{kg})$ of breeds.

The direct breed heritability $\left(h_{d}^{2}\right)$ values ranged $0.18-0.61$ across the breeds, lower in case of Hereford and Angus, than that of other breeds. These values are slightly higher than those reported by Meyer et al. (1994). Also, they are higher than obtained by Splan et al. (2002) who found value 0.14 . Maternal heritability value $\left(h_{m}^{2}\right)$ estimates are less $(0.07-0.38)$ than the direct heritability, and are similar to the finding of Mohiuddin (1993) who reported that the maternal heritability value of weaning weight tended to be lower than the direct heritability 
value. This result indicates a greater genetic influence of the calf than its dam for the trait. The opposite result was found by Splan et al. (2002) whose estimate of maternal heritability was slightly greater $(0.19)$ than the estimate for direct heritability (0.14). The total heritability values $\left(h_{T}^{2}\right)$ were between 0.09 and 0.35 which are similar to the values obtained by Meyer et al. (1994) and Vergara et al. (2009).

The direct-maternal genetic correlations $\left(r_{d m}\right)$ were high $(-0.52$ to -0.88$)$ and negative for all breeds. Similar results have been reported by Meyer $(1992,1993)$ and by Koots et al. (1999) who also found strong negative direct-maternal genetic correlations. Several estimates of direct-maternal correlation reported by Mohiuddin (1993) were negative, although they ranged from -0.78 to 0.25 . Also, similarly negative, but a somewhat lower correlations were reported by Splan et al. (2002) $\left(r_{d m}=-0.18\right)$ and Vergara et al. (2009), while Sullivan et al. (1999) assumed a zero correlation.

Table 3

Estimated variance and covariance components and heritability values of 205-day weight of calves

\begin{tabular}{|c|c|c|c|c|c|c|c|}
\hline Genetic parameters & HG & $\mathrm{HS}$ & AA & $\begin{array}{c}\text { Breed } \\
\mathrm{HE}\end{array}$ & $\mathrm{CH}$ & $\mathrm{BD}$ & $\mathrm{LI}$ \\
\hline $\begin{array}{l}\sigma_{\mathrm{p}}^{2} \text { phenotypic variance } \\
\sigma_{\mathrm{d}}^{2} \text { additive direct }\end{array}$ & 631 & 1250 & 980 & 1189 & 1515 & 1265 & 871 \\
\hline genetic variance & 384 & 461 & 173 & 224 & 892 & 697 & 302 \\
\hline $\begin{array}{l}\sigma_{\mathrm{e}}^{2} \text { residual variance } \\
\sigma_{\mathrm{pe}}^{2} \text { maternal permanent }\end{array}$ & 262 & 768 & 755 & 875 & 626 & 434 & 533 \\
\hline $\begin{array}{l}\text { environmental effect } \\
\mathrm{e}^{2} \text { the ratio of the } \\
\text { residual variance to }\end{array}$ & 42 & 69 & 0 & 80 & 30 & 30 & 72 \\
\hline $\begin{array}{l}\text { the phenotypic variance } \\
\sigma_{m}^{2} \text { maternal }\end{array}$ & $0.41 \pm 0.05$ & $0.61 \pm 0.05$ & $0.77 \pm 0.05$ & $0.74 \pm 0.03$ & $0.41 \pm 0.04$ & $0.34 \pm 0.11$ & $0.55 \pm 0.05$ \\
\hline $\begin{array}{l}\text { genetic variance } \\
\sigma_{\mathrm{dm}} \text { direct-maternal }\end{array}$ & 162 & 89 & 128 & 130 & 569 & 410 & 229 \\
\hline $\begin{array}{l}\text { genetic covariance } \\
\mathrm{c}^{2} \text { the ratio of the maternal } \\
\text { permanent environmental } \\
\text { variance to the phenotypic }\end{array}$ & -219 & -137 & -77 & -120 & -602 & -307 & -165 \\
\hline variance & $0.07 \pm 0.03$ & $0.06 \pm 0.02$ & $0.00 \pm 0.07$ & $0.07 \pm 0.05$ & $0.02 \pm 0.02$ & $0.02 \pm 0.03$ & $0.07 \pm 0.03$ \\
\hline $\mathrm{h}_{\mathrm{d}}^{2}$ direct heritability & $0.61 \pm 0.07$ & $0.37 \pm 0.06$ & $0.18 \pm 0.06$ & $0.19 \pm 0.04$ & $0.59 \pm 0.06$ & $0.55 \pm 0.17$ & $0.31 \pm 0.07$ \\
\hline $\mathrm{h}_{\mathrm{m}}^{\mathrm{a}}$ maternal heritability & $0.26 \pm 0.05$ & $0.07 \pm 0.03$ & $0.13 \pm 0.10$ & $0.11 \pm 0.08$ & $0.38 \pm 0.05$ & $0.32 \pm 0.07$ & $0.24 \pm 0.05$ \\
\hline$h_{m}^{2}+c^{2}$ & 0.33 & 0.13 & 0.13 & 0.18 & 0.40 & 0.32 & 0.31 \\
\hline $\mathrm{h}_{\mathrm{T}}^{2}$ total heritability & 0.22 & 0.24 & 0.12 & 0.09 & 0.18 & 0.35 & 0.19 \\
\hline $\begin{array}{l}r_{\mathrm{dm}} \text { direct-maternal } \\
\text { genetic correlation }\end{array}$ & $-0.88 \pm 0.04$ & $-0.68 \pm 0.10$ & $-0.52 \pm 0.31$ & $-0.70 \pm 0.23$ & $-0.84 \pm 0.03$ & $-0.57 \pm 0.11$ & $-0.63 \pm 0.09$ \\
\hline
\end{tabular}

HG: Hungarian Grey, HS: Hungarian Simmental, AA: Angus, HE: Hereford, CH: Charolais, BD: Blonde d'Aquitaine, LI: Limousin, $\mathrm{e}^{2}, \mathrm{c}^{2}, \mathrm{~h}_{\mathrm{d}^{\prime}}^{2} \mathrm{~h}_{\mathrm{m}^{\prime}}^{2}, \mathrm{r}_{\mathrm{dm}}, \pm=$ standard error (SE)

A difference in the genetic correlation between direct and maternal components of gain from birth to weaning can have several practical consequences. Negative estimates of direct-maternal genetic covariance have been reported for many beef cattle breeds are now included in national genetic evaluations of many breed associations (Splan et al. 2002). It is important because a negative genetic correlation between direct and maternal effects will reduce genetic progress (Heydarpour et al. 2008). Therefore, consideration of such effect in genetic evaluation requires reliable estimation. It is important to note that one should be careful about interpretation of this correlation estimates, especially in this case, because of 
small dataset of the evaluated breeds in our study. Covariances are generally more difficult to estimate and the quality of estimation is strongly depend on data structure (Heydarpour et al. 2008). According to the mentioned author, the increase of the proportion of cows without records in the population has a negative effect on reliability, increases the standard error and bias of the estimation. As in this study the proportion of cows without records was very low, practically zero, the result can be considered as significant previous data.

The genetic trend, estimated on the basis of breeding value differences from overall mean in a given year by breed are shown in Figure 2. As it can be seen with exception of Hungarian Grey no progress between 1976-88. Unstable genetic trend in most of breeds appeared between 1988-1996 when especially breeding value of Hungarian Grey, Hungarian Simmental and Blonde d'Aquitaine were varying, increasing, and then decreasing.

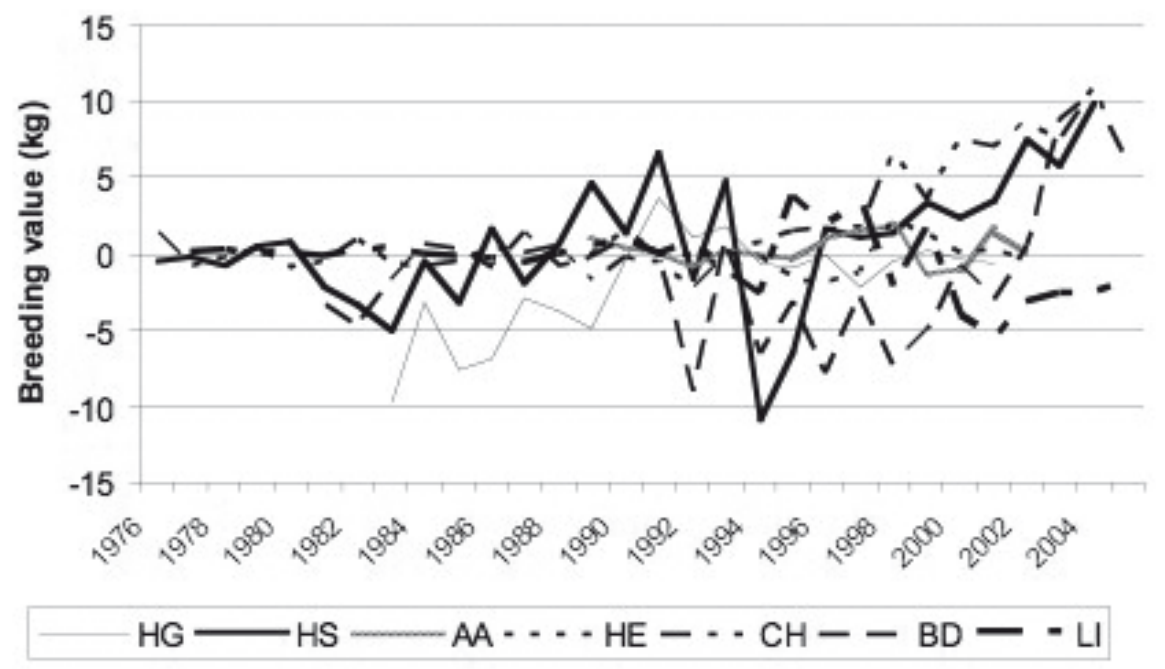

HG: Hungarian Grey, HS: Hungarian Simmental, AA: Angus, HE: Hereford, CH: Charolais, BD: Blonde d'Aquitaine, LI: Limousin

Figure 2

The genetic trend for 205-day weaning weight of different breeds

After 1996 genetic trends were almost positive, but the magnitudes varied considerably among breeds. Hungarian Simmental, Charolais and Blonde d'Aquitaine had faster genetic trends than the other breeds. These results are different from findings of Cundiff \& Van Vleck (1995) and Sullivan et al. 1999 who found that lighter breeds generally had faster genetic trends than heavier ones in pre weaning weight gain and weaning weight.

In conclusion, the findings of this study correspond to some other research results that sire, herd, age of dam at calving, birth year, season and sex of calf all have significant effect on 205-day weaning weight of calves in the studied breeds. These effects have to be taken into consideration when evaluating weaning results, doing genetic analyses and breeding value estimation for this trait. Adjustment of weaning weight according to these effects can decrease the bias and may increase the reliability of the genetic analysis. 
Breed differences and substantial overlap among breeds seems to exist for weaning performance in beef cattle population in Hungary. These differences can be important because weaned calf market specifications are similar for producers of all breeds, and management have to, therefore, compensate for breed differences.

Variance components, heritability values, and direct-maternal genetic correlations of 205day weaning weight to some extent were similar for purebred populations of different beef cattle breeds in Hungary, generally corresponding to the results reported by several authors. As using of own heritability values of a given population for a trait, such as weaning weight is basic requirement, these estimates can help to improve the genetic evaluation programmes of different beef cattle breeds in the country. Moreover direct-maternal genetic correlations can be important as many studies suggested that both direct and maternal additive genetic effects should be taken into consideration when setting selection aim.

The results of this study show that genetic trends vary among breeds involved in the evaluation. This fact indicates either that selection objectives or selection efficiencies are variable. The results obtained in genetic trend in the case of different breeds support the opinion that breeders from any breed likely target the average commercial cow.

\section{Acknowledgements}

The authors are grateful to the project TÁMOP-4.2.2.A-11/KONV-2012-003 for funding this work.

\section{References}

Amer PR, Kemp RA, Smith C (1992) Genetic differences among the predominant beef cattle breeds in Canada: an analysis of published results. Can J Anim Sci 72, 759-771

Boldman KG, Kriese LA, Van Vleck LD, Kachman SD (1993) A manual for use of MTDFREML. A set of programs to obtain estimates of variances and covariances. USDA-ARS, Clay Center, NE, USA

Cundiff LV, Gregory KE, Long CR (1975) Genetic variation among and within herds of Angus and Hereford catttle. J Anim Sci 41, 1270-1278

Cundiff LV, Van Vleck LD (1995) Across breed considerations in prediction of genetic values. Proc. 5th Genetic Prediction Workshop. Beef Improvement Federation, Kansas City. MO, USA, 120-132

Cundiff LV, Gregory KE, Koch RM (1998) Germplasm evaluation in beef cattle-cycle IV: birth and weaning traits. J Anim Sci 76, 2528-2535

Dodenhoff J, Van Vleck LD, Gregory KE (1999) Estimation of direct, maternal, and grandmaternal genetic effects for weaning weight in several breeds of beef cattle. J Anim Sci 77, 840-845

Gregory KE, Smith GM, Cundiff LV, Koch RM, Laster DB (1979) Characterization of biological types of cattlecycle III: I. Birth and weaning traits. J Anim Sci 48, 271-279

Harvey WR (1990) User's guide for LSLMW and MIXMDL PC-2 version Mixed Model Least-Squares and Maximum Likelihood Computer Program. The Ohio State University. Colombus, OH, USA

Heydarpour M, Schaeffer LR, Yazdi MH (2008) Influence of population structure on estimates of direct and maternal parameters. J Anim Breed Genet 125, 89-99

Koots KR, Gibson JP, Smith C, Wilton JW (1994) Analyses of published genetic parameter estimates for beef production traits. 1. Heritability. Anim Breed Abstr 62, 309-338

Meyer K (1992) Variance components due to direct and maternal effects for growth traits of Australian beef cattle. Livest Prod Sci 31, 179-204 
Meyer K, Carrick MJ, Donnelly BJ (1993) Genetic parameters for growth traits of Australian beef cattle from a multibreed selection experiment. J Anim Sci 71, 2614-2622

Meyer K, Carrick MJ, Donnelly BJ (1994) Genetric parameters for milk production of Australian beef cows and weaning weight of their calves. J Anim Sci 72, 1155-1165

Meyer K (1998) DFREML. Version 3.0. User notes, University of New England, Armidale, Australia

Minyard JA, Dinkel CA (1965) Weaning weight of beef calves as affected by age and sex of calf and age of dam. J Anim Sci 24, 1067-1071

Mohiuddin G (1993) Estimates of genetic and phenotypic parameters of some performance traits in beef cattle. Anim Breed Abstr 61, 495-522

Notter DR, Cundiff LV, Smith GM, Laster DB, Gregory KE (1978) Characterization of biological types of cattle. VII. Milk production in young cows and transmitted and maternal effects on preweaning growth of progeny. J Anim Sci 46, 908-921

Pell EW, Thayne WV (1978) Factors influencing weaning weight and grade of West Virgina beef calves. J Anim Sci 46, 596-603

Rossi DJ, Kress DD, Tess MW, Burfening PJ (1992) Correcting bias from the standard linear adjustment of weaning weight to an age-constant basis for beef calves. J Anim Sci 70, 1333-1341

Rumph JM, Van Vleck LD (2004) Age-of-dam adjustment factors for birth and weaning weight records of beef cattle: a review. Genet Mol Res 3, 1-17

Sellers HI, Willham RL, DeBaca RC (1970) Effect of certain factors on weaning weight of beef calves. J Anim Sci 31, 5-12

Smith GM, Laster DB, Gregory KE (1976) Characterization of biological types of cattle. I. Dystocia and preweaning growth. J Anim Sci 43, 27-36

Splan RK, Cundiff LV, Dikeman ME, Van Vleck LD (2002) Estimates of parameters between direct and maternal genetic effects for weaning weight and direct genetic effects for carcass traits in crossbred cattle. J Anim Sci 80, 3107-3111

Sullivan PG, Wilton JW, Miller SP, Banks LR (1999) Genetic trends and breed overlap derived from multiplebreed genetic evaluations of beef cattle for growth traits. J Anim Sci 77, 2019-2027

Szabó F, Nagy L, Dákay I, Márton D, Török M, Bene Sz (2006) Effects of breed, age of dam, birth year, birth season and sex on weaning weight of beef calves. Livest Sci 103, 181-185

Vergara OD, Ceron-Muñoz MF, Arboleda EM, Orozco Y, Ossa GA (2009) Direct genetic, maternal genetic, and heterozygosity on weaning weight in a Colombian multibreed beef cattle population. J Anim Sci 7, 516-521

Received 13 May 2011, accepted 15 May 2012.

Corresponding author:

Ferenc Szabó

email: szf@mtk.nyme.hu

University of West Hungary, H-9200 Mosonmagyaróvár, Vár 2., Hungary 